\title{
An Analysis of the Current Situation of the Research on the Influencing Factors of M \& A Performance of Listed Companies
}

\author{
Guohui Zhang ${ }^{1, *}$, Dongchuan Lin ${ }^{1}$, Yeling Wang ${ }^{1}$, Bingxi Lei ${ }^{1}$ \\ ${ }^{1}$ Business and Tourism School, Sichuan Agricultural University, Sichuan, 610000, China
}

\begin{abstract}
M \& A was an important means to promote the transformation and upgrading of traditional industries, and also an important way to improve the degree of industrial concentration and speed up the transformation of industrial development mode. As a direct embodiment of the efficiency of M \& A, the performance of M \& A has been widely concerned by scholars. This paper introduced the concept of $M \&$ A performance and motivation of $\mathrm{M} \& \mathrm{~A}$, used Citespace to analyze 749 papers on $\mathrm{M} \&$ A performance from CNKI core journals from 2000 to 2020, The research focus and frontier of M \& A performance a analyzed by keyword clustering and keyword variation, and analyzed the research results of external environment, internal environment, M \& A characteristics and external intermediary agencies which affect M \& A performance, Finally, the possible direction of future research was proposed.
\end{abstract}

\section{Performance and Motivation of M \& A}

$\mathrm{M} \& \mathrm{~A}$ is the abbreviation of merger and acquisition. Among them, merger is also called absorption merger, which means that two or more enterprises with independent accounting form one enterprise through reorganization. It is usually a strong enterprise to absorb another or more relatively weak enterprises. Acquisition means that one enterprise purchases part or all of the assets and shares of another enterprise by paying cash or delivering securities, so as to realize the acquisition of its control or even ownership. The academic circles have not yet strictly distinguished the two, so they are collectively referred to as $M$ \& A. Because of China's special economic background, the development of the securities market is not mature, and the corresponding policies and systems are not perfect, the concept of $M$ \& $\mathrm{A}$ is more ambiguous, In practice, the concept of $\mathrm{M} \& \mathrm{~A}$ has not been completely differentiated, which usually includes equity acquisition, asset acquisition, debt restructuring, asset replacement, etc.

Based on the research of Chinese scholar Bailiang Cai [1], this paper defines $M$ \& A performance as: the general term of the actual economic effect of enterprises after $\mathrm{M} \& \mathrm{~A}$ activities. Through the summary of the existing literature, we can further reveal the performance of $\mathrm{M} \& \mathrm{~A}$ from macro and micro perspectives. From a macro point of view, M \& A performance refers to the interaction between the main party and the capital market caused by $M$ \& A, promoting the upgrading of the industrial structure of the industry, optimizing the allocation of social resources, etc. From the micro point of view, $M \&$ A performance refers to the impact of $M$ $\&$ A activities on the financial performance, operating efficiency and development ability of enterprises, such as the changes of stock prices and financial indicators of listed companies. In addition, according to whether it can be quantified, M \& A performance can be divided into financial M \& A performance and non-financial M \& A performance. Considering the availability of data and the feasibility of the study, the current research mainly focuses on the micro level of $\mathrm{M} \& \mathrm{~A}$ performance and financial $M$ \& $A$ performance, so the $M$ \& $A$ performance mentioned in this paper also refers to the micro level of $\mathrm{M} \& \mathrm{~A}$ performance and financial $\mathrm{M} \& \mathrm{~A}$ performance.

A large number of scholars have studied the motivation of $\mathrm{M} \& \mathrm{~A}$. the most representative theories include principal-agent theory, scale economy theory, resource-based theory, transaction cost theory, market advantage theory and so on [2]. Jensen and Meckling (1976) believe that principal-agent theory is the motivation of $\mathrm{M} \& \mathrm{~A}$. For the public sector and private enterprises, the main purpose of $M \& A$ is to increase market share and expand market scale [3]. At the same time, Chinese scholar Shanshan Pei believes that the purpose of M \& A may be to pursue returns to scale and help enterprises obtain more benefits [4]. Han Zhang proposed that the main motivation for Chinese enterprises to carry out $\mathrm{M} \& \mathrm{~A}$ transactions is to promote the diversified development of enterprises, promote the upgrading of industrial structure, and finally achieve synergy [5].

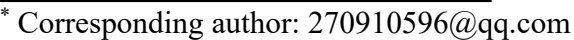




\section{Research Hotspots and Frontier of M\& A Performance based on Citespace Kno wledge Graph Analysis}

\subsection{Research Method and Data Sources}

Citespace is a java program for citation analysis. Relying on the combination of database and analysis software, Citespace can find key points, draw knowledge map, realize information visualization analysis, show the development trend of a discipline or knowledge domain in a certain period, and form the evolution process of several research frontier fields. This paper selects journal papers in CNKI's library, With "M\&A performance" or "M\&A value" as the theme, the journal sources are limited to SCI, EI, Peking University Core, CSSCI and CSCD, The time is set from 2000 to 2020.Finally, 749 results were obtained, Through manual screening, irrelevant documents were eliminated, and finally 634 results were obtained. By converting the data into Refworks format and imported into Citespace software as the sample for this article.

\subsection{Analysis of M\&A Performance Knowledge Graph}

\subsubsection{Trend analysis of articles published}

The trend analysis of articles published can reveal whether the research field has received extensive attention from scholars. At the same time, the trend of papers in different periods also reflects the political and economic background of the stage to a certain extent, which can indicate whether the field has research value. According to Figure 1, It can be seen that the volume of publications has been increasing year by year as a whole. It can be roughly divided into three stages: $2000-2007$ is the initial stage. With China's formal accession to the world trade organization, China's M \& A market also ushered in a boom, and $\mathrm{M} \& \mathrm{~A}$ has become an important way to promote industrial transformation and upgrading in China. Therefore, more and more scholars began to systematically study $M$ \& A performance in this period. The period from 2008 to 2015 is a period of rapid development, in which the research on $\mathrm{M} \& \mathrm{~A}$ performance in China shows a steady growth. After the global economic crisis in 2008, Chinese enterprises are in urgent need of recovery and adjustment to adapt to the new market changes. At the same time, under the guidance of China's policy, the role of $\mathrm{M} \& \mathrm{~A}$ in promoting industrial upgrading is more obvious. During this period, there was the second wave of $\mathrm{M} \& \mathrm{~A}$ in China, 2016-2020 is a stable development stage, and the number of papers on $\mathrm{M} \& \mathrm{~A}$ performance in this stage is stable at more than 50, reaching 76 in 2020, which shows that scholars pay more and more attention to $\mathrm{M} \&$ A performance research.

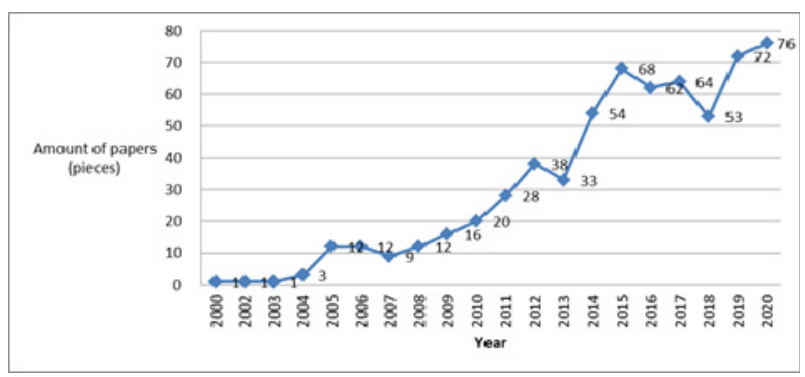

Fig. 1. Trends in the publication of CNKI China's M\&A performance research results.

\subsubsection{Research hotspot analysis}

Table 1 lists the top ten keywords of $\mathrm{M} \& \mathrm{~A}$ performance research. The frequency of keywords indicates how many times the keywords appear in the sample. The centrality of keywords indicates the collinearity of the keywords and $\mathrm{M} \& \mathrm{~A}$ performance. We can see that, M\&A performance, cross-border M\&A, listed company, influencing factors, corporate governance, information asymmetry, political connections, etc. all have a high frequency and centrality, It shows that cross-border M\&A, corporate governance and information asymmetry are the hotspots of the research of M\&A performance. The keyword centrality of listed companies reaches 0.4 , which indicates that listed companies are the main research objects of $M \& A$ performance.

Table 1. High-frequency keywords in M\&Aperformance research

\begin{tabular}{|c|c|c|}
\hline Keyword & Frequency & Centrality \\
\hline M\&A performance & 385 & 0.3 \\
\hline Cross-border M \& A & 56 & 0.14 \\
\hline Listed company & 51 & 0.4 \\
\hline Influencing factors & 49 & 0.11 \\
\hline Overseas M \& A & 36 & 0.11 \\
\hline Corporate Governance & 22 & 0.15 \\
\hline Payment method & 21 & 0.04 \\
\hline Ownership structure & 21 & 0.06 \\
\hline Political connection & 14 & 0.13 \\
\hline Information asymmetry & 12 & 0.21 \\
\hline
\end{tabular}

\subsubsection{Research frontier analysis}

Citespace is used to analyze the keyword mutation of $\mathrm{M}$ \& A performance. The keywords with higher emergence intensity in the period can represent the emerging research trend in this field. In this paper, the top 15 keywords of mutation intensity are extracted. As can be seen from Table 2, government intervention, crossborder M \& A performance, private enterprises, cultural distance, payment method and government intervention are the new research frontiers in recent years, with high mutation intensity. Among them, the mutation degree of cross-border $\mathrm{M} \&$ A performance reaches 3.86 , and the mutation degree of cross-border $M$ \& A reaches 4.29. It can be seen that cross-border M \& A is the forefront of current research. With the deepening of China's opening 
up, cross-border M \& A will attract scholars to conduct more in-depth research.

Table 2. Top 15 Keywords with the Strongest Citation Bursts

\begin{tabular}{|c|c|c|c|c|}
\hline Keywords & Year & Strength & Begin & End \\
\hline Empirical research & 2000 & 3.73 & 2005 & 2020 \\
\hline Horizontal M\&A & 2000 & 1.86 & 2005 & 2020 \\
\hline Types of M \& A & 2000 & 2.65 & 2007 & 2020 \\
\hline Listed company & 2000 & 2.37 & 2007 & 2020 \\
\hline Industrial effect & 2000 & 1.89 & 2008 & 2020 \\
\hline Industrial Innovation & 2000 & 1.89 & 2013 & 2020 \\
\hline Separation of two rights & 2000 & 2.23 & 2014 & 2020 \\
\hline Cross border M \& A & 2000 & 4.29 & 2016 & 2020 \\
\hline Government intervention & 2000 & 2.09 & 2017 & 2020 \\
\hline Payment method & 2000 & 2.42 & 2017 & 2020 \\
\hline Cultural distance & 2000 & 2.78 & 2017 & 2020 \\
\hline Private enterprise & 2000 & 2.21 & 2017 & 2020 \\
\hline Enterprise life cycle & 2000 & 1.92 & 2017 & 2020 \\
\hline Cross border M \& A & 2000 & 3.86 & 2018 & 2020 \\
\hline Political connection & 2000 & 2.08 & 2018 & 2020 \\
\hline
\end{tabular}

\section{The Influencing Factors of M \& A Performance}

\subsection{The external environment of the enterprise}

The external environment refers to the external objective conditions for the survival and development of enterprises [6]. From the perspective of the macro environment, political genes will affect the dominant trend of mergers and acquisitions, and the unreasonable dominance tendency of companies with stronger political genes will adversely affect the performance of mergers and acquisitions [7], if an M\&A transaction takes place in a period of strong uncertainty of economic policy, the more unsatisfactory the long-term market reaction after the merger of the main merger party is [8]. The greater the language difference between the two parties, the worse the performance of the acquirer [9]. For the external micro-environment, higher accounting information can better help enterprises evaluate the value of the merged party and get higher M\&A performance [10]. The more intense the product market competition that the target enterprises participate in, the better the performance of $\mathrm{M} \& \mathrm{~A}$ will be [11].

\subsection{The internal environment of the enterprise}

The internal environment of an enterprise refers to the total of the internal conditions and atmosphere that an enterprise has in order to ensure its normal operation within the scope of control [6]. According to the characteristics of directors, if there is a link of directors between the acquirer and the target company, the acquirer will achieve better long-term M\&A performance [12]. In addition, when the headquarters of the company has independent directors from the region where the target company is located, the success rate and M \& A performance will be improved [13]. From the perspective of managers' ability, when managers' ability is strong, $\mathrm{M} \& \mathrm{~A}$ enterprises have more opportunities to obtain better M \& A performance [14]. If both parties have relevant human capital, the higher the success rate of the merger, the higher the return and performance of M\&A [15].

\subsection{Features of M\&A transactions}

The characteristics of M\&A transactions are the transaction behaviors and modes presented by enterprises in M\&A activities. Starting from the M \& Aenterprises themselves, if they have more experience [16] and better M \& A capabilities [17], the greater the value and performance will be obtained after the merger. From the main and side with the relationship between the mergering party and the merged party, related-party mergers and acquisitions have a significant negative effect on the M \& A performance, and the main merging party's accounting robustness significantly weakens this effect [18]. In the process of M\&A transactions, under the condition of cash payments and mixed with assets pay cases, M\&A performance is relatively stable [19]. The use of stock payment methods will promote the long-term $\mathrm{M} \& \mathrm{~A}$ performance, while bond financing will reduce the long-term $\mathrm{M} \& \mathrm{~A}$ performance [20].

\subsection{External intermediary entities}

In $\mathrm{M} \& \mathrm{~A}$ transactions, intermediary agencies can use their own information resources and practical experience to improve the success rate of $\mathrm{M} \& \mathrm{~A}$ transactions. Top financial advisors can reduce $M \& A$ premiums and increase M\&A performance in the M\&A wave [21]. Compared with the financial adviser without "relationship", the financial adviser with "relationship" can significantly improve the M \& A performance, and the degree of closeness of the relationship is positively correlated with the M \& A performance [22]. From the perspective of auditor, the joint auditor employed by both parties can effectively alleviate the degree of information asymmetry, reduce the uncertainty of $\mathrm{M} \&$ A transactions and improve $M \&$ A performance [23]. In addition, in non-linked M\&As, auditors can use their professional capabilities to reduce information asymmetry, thereby significantly improving M\&A performance [24].

\section{Conclusion}

This paper combs the existing research progress from four aspects: the concept of $\mathrm{M} \& \mathrm{~A}$ performance, the motivation of $\mathrm{M} \& \mathrm{~A}$, research hotspots and frontier of $\mathrm{M} \& \mathrm{~A}$ performance, and influencing factors of $\mathrm{M} \& \mathrm{~A}$ performance. Obviously, the research results on the influencing factors of $\mathrm{M} \& \mathrm{~A}$ performance have been quite rich, covering a wide range of fields, which provides rich theoretical support for the following research. In terms of influencing factors, the current research is more about the influence of single factor or subject on $M$ \& A performance. For multiple factors and different types of subjects, whether they can influence M $\&$ A performance through linkage effect and cooperation 
effect is worthy of further research. At the same time, with the deepening of economic globalization and the continuous improvement of China's reform and openingup policy, more and more enterprises rely on the implementation of cross-border $\mathrm{M} \& \mathrm{~A}$ to find international resources and develop the international market, so the performance of cross-border M \& Ais also worthy of in-depth study.

\section{Acknowledgement}

This paper was supported by the Sichuan Center for County Economic Development Research (XY2019029), Project of Sichuan Center for the Revolution Old Area Development (SLQ2019C-17).

\section{References}

1. B.L.Cai,. Financial research, 07, 124-133,(2007)

2. M. C .Jensen,. W. Meckling, Journal of Financial Economics, 2, 278-286(1976)

3. M. Vojislav, P .Gordon, Liu Y. Private and Public Merger Waves (2013)

4. S. Pei Commercial economy, 03, 73-74(2014)

5. H. Zhang, Business manager, 8,56(2017)

6. X. M .Li,Jiangsu Business Theory, 05, 131133(2005)

7. Y. Wang, W. Xie, Y. Qiao, et al. Management world, 8, 02-114(2014)

8. Y. Tong, Y .Lin, X, Li., Journal of Beijing University of Technology, 23,53-66,(2021)

9. L. Li, Y. He, Tang Xiaoyan, Financial research, 06, 141-153(2018)

10. M .F. Mcnichols, S R. Stubben, Review of Accounting Studies, 20, 110-140(2015)

11. J. Wang, S. Ma, Liaoning economy, 11, 40-41(2020)

12. S. Chen, G. Jiang, C. Lu, Management world, 12,117-132(2013)

13. C. Liu, S. Li, L. Sun,management world, 3,124136(2015)

14. M. Xiao,H. T .Li, Management world, 6, 184$185(2017)$

15. K .H .Lee, D. C .Mauer,Journal of Financial Economics, 129,111-135(2018)

16. I. R. P. Cuypers, Cuypers. Y, X. Martin Strategic Management Journal,38,609-625(2017)

17. L, Song, J. Zhou, Journal of Shenyang University of Technology,13, 521-526 (2020)

18. Q. Q. Tang, H. W. Han, Nankai management review, 21,23-34 (2018)

19. J. G. Ge, Accounting research, 09, 74-80 + 97(2015)

20. F. L Zhang, Y. Li, F. Liu,Economic issues, 07,104110 (2018)

21. J.A. Faias, Ssrn Electronic Journal, 18, 443-456 (2017)
22. Q. Y. Li, X.Q. Liu, Y. L. Huang, Finance and trade economics, 38,99-114(2014)

23. J. Chircop, S .Johan, M. Tarsalewska, Journal of International Financial Markets Institutions \& Money, 40, 544-578(2017)

24. W. J. Li, X. Y.Jiang, G. M. Gong, Friends of accounting, 12,108-113 (2017) 